\title{
A case of anti-gamma-aminobutyric acid-B receptor encephalitis coexisting with ankylosing spondylitis
}

\author{
Aiqing $\mathrm{Li}^{1} \cdot$ Weihua Feng ${ }^{2} \cdot$ Jingfang Lin ${ }^{1} \cdot$ Dong Zhou ${ }^{1} \cdot$ Zhen Hong $^{1}$
}

Received: 22 October 2019 / Accepted: 9 March 2020 / Published online: 3 April 2020

(C) The Author(s) 2020

\begin{abstract}
Dear Editor,
Anti-gamma-aminobutyric acid-B receptor $\left(\mathrm{GABA}_{\mathrm{B}}-\mathrm{R}\right)$ encephalitis, autoimmune encephalitis (AE) associated with anti-neuronal cell surface antibodies, presents with prominent seizures, behavioral changes, and cognitive deficits. Half of the cases of anti-GABA $A_{B}-R$ encephalitis have been associated with tumors, especially small-cell lung cancer [1]. Ankylosing spondylitis (AS) is a chronic autoimmune inflammatory condition affecting the spine and sacroiliac joint [2], which leads to back pain and progressive spinal stiffness. However, the co-occurrence of anti-GABA $A_{B}-\mathrm{R}$ encephalitis and $\mathrm{AS}$ has never been reported. Here, we provide a case report of anti$\mathrm{GABA}_{\mathrm{B}}-\mathrm{R}$ encephalitis coexisting with $\mathrm{AS}$ for the first time. A Chinese man, whose HLA-B27 and anti$\mathrm{GABA}_{\mathrm{B}}-\mathrm{R}$ antibodies were positive, was diagnosed with anti-GABA $A_{B}-R$ encephalitis and AS.
\end{abstract}

Aiqing Li and Weihua Feng contributed equally to this work.

Electronic supplementary material The online version of this article (https://doi.org/10.1007/s10072-020-04336-2) contains supplementary material, which is available to authorized users.

Zhen Hong

hongzhengoog@aliyun.com

Aiqing Li

1365708072@qq.com

Weihua Feng

FWH0825@163.com

Jingfang Lin

906022781@qq.com

Dong Zhou

zhoudong66@yahoo.de

1 Department of Neurology, West China Hospital, Sichuan University, Chengdu, Sichuan, People's Republic of China

2 Department of Experimental Medicine, West China Hospital, Sichuan University, Chengdu, Sichuan, People's Republic of China
A 34-year-old man presented with his first generalized tonic-clonic seizure (GTCS) lasting for $1 \mathrm{~min}, 20$ days before this admission. After a neurological evaluation and head computed tomography (CT) scan in the emergency department, he was prescribed sodium valproate $500 \mathrm{mg}$ twice daily. However, he experienced another GTCS which lasted for $3 \mathrm{~min}, 20$ days after his first GTCS. Other symptoms included psychiatric abnormalities, such as irritability, delirium, and behavioral changes, in addition to more frequent seizure attacks observed on the following days. The patient experienced GTCSs one-to-four times daily with each episode lasting for 1-3 min. He reported a history of lower back pain and fatigue for 2 years without any evaluation or treatment. An aunt of the patient had a history of ankylosing spondylitis. Neurological examination showed a decline in cognitive function, which mainly affected short-term memory, and disorientation in time and space was revealed. The results of cranial nerve (the first cranial nerve was not tested), motor system, tendon reflexes, meningeal irritation sign, and Babinski sign examinations were generally normal. It was not possible to completely examine the patient's sensory system or motor coordination. $\mathrm{GABA}_{\mathrm{B}}-\mathrm{R}$ antibodies were found in the serum (1:10) and cerebrospinal fluid (CSF) (1:10) using a Cytometric Bead Array (Fig. 1) (Euroimmun, Lubeck, Germany). Serum and CSF were both negative for antibodies against neuronal surface antigens, including antibodies to N-methyl-D-aspartate (NMDA) receptors, leucine-rich glioma-inactivated protein 1 (LGI1), contactin-associated protein-like 2 (CASPR2), $\alpha$-amino-3-hydroxy-5-methyl-4isoxazolepropionic acid receptor (AMPAR), dipeptidylpeptidase-like protein-6 (DPPX), and metabotropic glutamate receptor 5 (mGluR5). Tests for paraneoplastic antibodies (anti-Hu, anti-Yo, anti-Ri, anti-GAD, anti-PCA2, anti-Ma2/Ta, anti-CV2/CRMP5, anti-ANNA-3, and antiamphiphysin) in serum and CSF were negative. Antivoltage-gated calcium channel (VGCC) antibodies (using radioimmunoprecipitation) were negative in serum, as 
Fig. 1 Antibody tests of the patient. a Cerebrospinal fluid showing binding to the surface of cells expressing anti-gammaaminobutyric acid-B receptors $\left(\mathrm{GABA}_{\mathrm{B}}-\mathrm{Rs}\right)(1: 10)$. b Serum showing binding to the surface of cells expressing $\mathrm{GABA}_{\mathrm{B}}-\mathrm{Rs}$ (1:10) (scale bar $10 \mu \mathrm{m})$
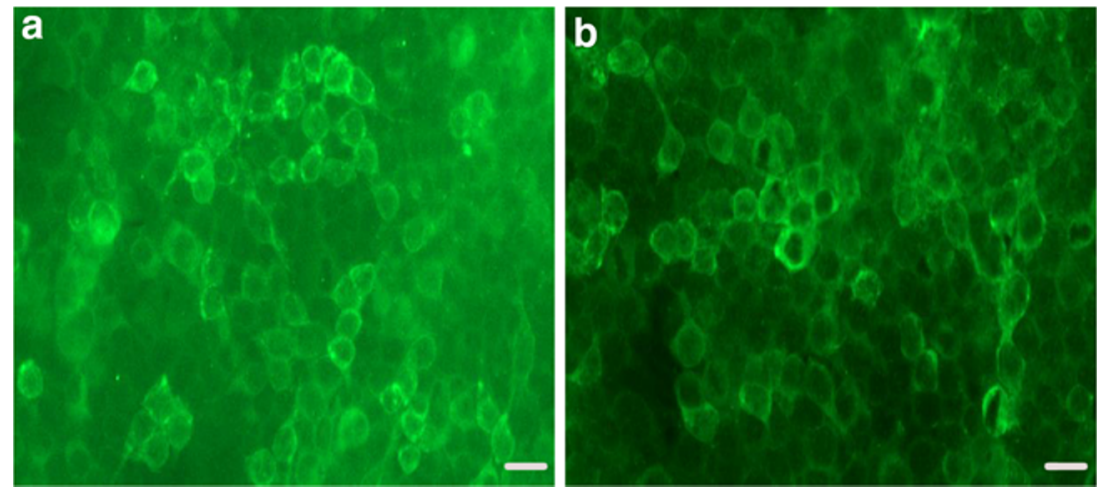

well. The patient's total protein level, glucose level, white blood count, and IgG synthetic rate of CSF specimen were unremarkable. No infectious etiology, such as bacteria, fungus, Mycobacterium tuberculosis, or cryptococcus, was detected in the CSF.

Laboratory blood testing, including routine blood tests, routine biochemical evaluations, and tests for rheumatoid factors and rheumatological autoantibodies (anti-cyclic citrullinated peptides antibodies, anti-nuclear antibodies, anti-double-stranded DNA antibodies, anti-ENA autoantibody profile, and antiphospholipid antibodies); thyroid profile (triiodothyronine, thyroxine, thyroid-stimulating hormone); tumor biomarkers (prostate-specific antigen (PSA) and $\alpha$ fetoprotein (AFP), carcinoembryonic antigen (CEA), carbohydrate antigen (CA)125, CA19-9, CA724); treponema pallidum; and viral serological tests (herpes simplex virus $1 / 2$, human immunodeficiency virus, human cytomegalovirus, and Epstein-Barr virus) were all negative or normal, except for C-reactive protein, which was $25 \mathrm{mg} / \mathrm{L}$ (normal value $<5 \mathrm{mg} / \mathrm{L}$ ). A genetic study revealed that the patient was HLAB27-positive (flow cytometry) (Supplemental Fig. 1). CT scans of the abdomen and chest conducted upon this admission to detect an underlying tumor revealed no tumor signs. Fluid-attenuated inversion recovery and T1- and T2-weighted magnetic resonance imaging (MRI) of the patient's brain were unremarkable (Supplemental Fig. 2 A-C). An electroencephalogram (EEG) documented a frontal slowing wave but without epileptic discharge (Supplemental Fig. 2 D-E). A spinal $\mathrm{X}$-ray showed hyperosteogeny of the spine and narrowing of the lumbar intervertebral space with blurred space in the bilateral sacroiliac joints (Fig. 2). An MRI of the sacroiliac joints revealed narrow spaces between the bilateral sacroiliac joints with rough articular surfaces and abnormal signals below the articular surface, which indicated the possibility of AS. Additional laboratory results are shown in Table 1.

Immune therapy (intravenous methylprednisolone, $1000 \mathrm{mg}$ /day for 5 days), accompanied by oral valproate and oxcarbazepine, was initiated immediately after the definite diagnosis 27 days after onset. Then, oral prednisolone was started at $60 \mathrm{mg} /$ day and was reduced by $5 \mathrm{mg}$ weekly.
The response to immunotherapy and the combination of anti-epileptic drugs were reasonably good, as indicated by the absence of seizures. The cognitive impairments and behavior abnormalities improved significantly after 4 weeks of immune therapy. Stiffness and pain in the lower back persisted because the patient did not accept nonsteroidal anti-inflammatory drugs that could have alleviated the discomfort. The $\mathrm{GABA}_{\mathrm{B}}-\mathrm{R}$ antibodies were measured again after 1 month of immune therapy and showed negative results in both the CSF and serum. Chest and abdominal CT scans were performed, revealing no tumor signs 6 months and 1 year after disease onset. The patient's symptoms resolved, and he reported no additional seizure episodes upon follow-up.

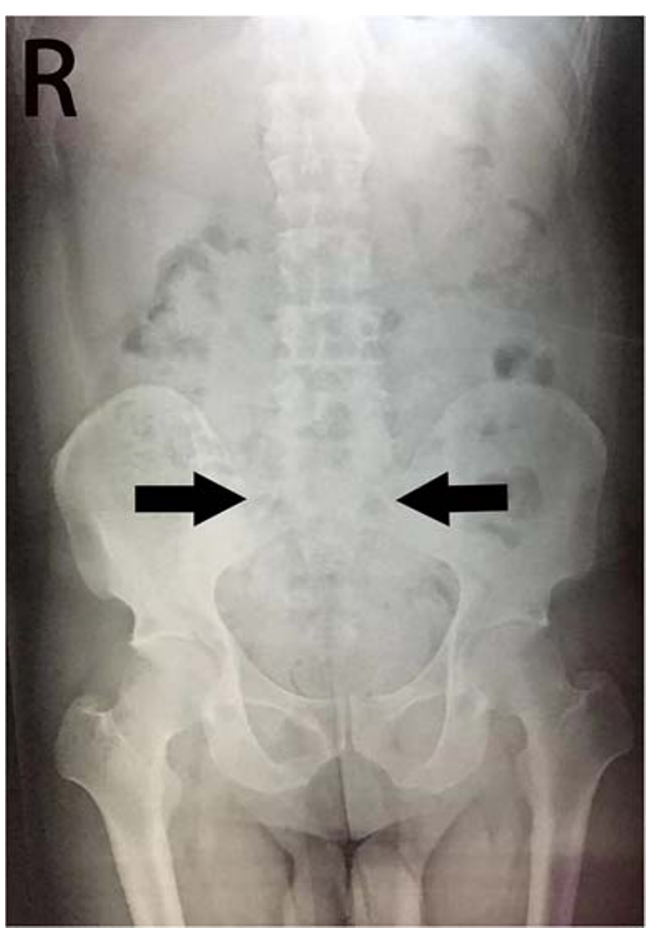

Fig. 2 Spinal X-rays of the patient. Spinal x-rays show bilateral sacroiliitis with blurred articular surfaces (arrows), indicating the possibility of ankylosing spondylitis 
Table 1 Results of laboratory examinations in the patient

\begin{tabular}{|c|c|}
\hline Cerebrospinal fluid & $(-)$ \\
\hline Glucose & $(-)$ \\
\hline Protein & $(-)$ \\
\hline Fungus (smear/culture) & $(-/-)$ \\
\hline Bacteria (smear/culture) & $(-/-)$ \\
\hline Acid-fast bacilli cultures & $(-)$ \\
\hline Malignant cell & $(-)$ \\
\hline Flow cytometry & $(-)$ \\
\hline a Neuronal cell surface antibodies & (CSF/serum) \\
\hline Anti-NMDAR & $(-/-)$ \\
\hline Anti-GABA ${ }_{B}$ & $(+/+)$ \\
\hline Anti-LGI1 & $(-/-)$ \\
\hline Anti-CASPR2 & $(-/-)$ \\
\hline Anti-AMPAR & $(-/-)$ \\
\hline Anti-DPPX & $(-/-)$ \\
\hline Anti-mGluR5 & $(-/-)$ \\
\hline${ }^{\mathrm{a}}$ Onconeuronal antibodies & (CSF/serum) \\
\hline Anti-Hu & $(-/-)$ \\
\hline Anti-Ri & $(-/-)$ \\
\hline Anti-Yo & $(-/-)$ \\
\hline Anti-GAD & $(-/-)$ \\
\hline Anti-PCA2 & $(-/-)$ \\
\hline Anti-Ma2/Ta & $(-/-)$ \\
\hline Anti-CV2/CRMP5 & $(-/-)$ \\
\hline Anti-ANNA3 & $(-/-)$ \\
\hline Anti-amphiphysin & $(-/-)$ \\
\hline${ }^{\mathrm{b}}$ Anti-VGCC antibodies & $(-)$ \\
\hline \multicolumn{2}{|l|}{ Hematologic test results } \\
\hline HLA-B27 gene & $(+)$ \\
\hline Human cytomegalovirus & $(-)$ \\
\hline Epstein-Barr virus & $(-)$ \\
\hline $\begin{array}{l}\text { Human immunodeficiency } \\
\text { virus }\end{array}$ & $(-)$ \\
\hline Syphilis & $(-)$ \\
\hline Mycobacteria & $(-)$ \\
\hline Prostate-specific antigen & $(-)$ \\
\hline$\alpha$-fetoprotein & $(-)$ \\
\hline Carcinoembryonic antigen & $(-)$ \\
\hline Carbohydrate antigen 125 & $(-)$ \\
\hline Carbohydrate antigen 19-9 & $(-)$ \\
\hline Carbohydrate antigen 724 & $(-)$ \\
\hline Anti-nuclear antibody & $(-)$ \\
\hline Anti-keratin antibodies & $(-)$ \\
\hline Anti-dsDNA & $(-)$ \\
\hline Anti-Smith antibodies & $(-)$ \\
\hline Anti-SS-A and SS-B & $(-)$ \\
\hline Anti-ANCA & $(-)$ \\
\hline Anti-anticardiolipin antibodies & $(-)$ \\
\hline Rheumatoid factor & $(-)$ \\
\hline Anti-CCP & $(-)$ \\
\hline Anti-topoisomerase antibody & $(-)$ \\
\hline
\end{tabular}

Table 1 (continued)

\begin{tabular}{ll} 
Anti-Jo-1 & $(-)$ \\
Anti-RNP-70 & $(-)$ \\
Anti-centromere B & $(-)$ \\
Anti-streptolysin O & $(-)$ \\
C-reactive protein & $25 \mathrm{mg} / \mathrm{L}$ (normal value $<5 \mathrm{mg} / \mathrm{L}$ ) \\
Erythrocyte sedimentation rate & $(-)$ \\
Triiodothyronine & $(-)$ \\
Thyroxine & $(-)$ \\
Free triiodothyronine & $(-)$ \\
Free thyroxine & $(-)$ \\
Thyroid-stimulating hormone & $(-)$ \\
Thyroid globulin antibody & $(-)$ \\
Thyroid peroxidase antibody & $(-)$ \\
\hline
\end{tabular}

${ }^{\text {a }}$ Cell base assay (EUROIMMUN, Germany)

${ }^{\mathrm{b}}$ Radioimmunoprecipitation (EUROIMMUN, Germany)

$\mathrm{N}$-methyl-D-aspartate receptor, $N M D A R$; gamma-aminobutyric acid-B receptor, $G A B A B$; leucine-rich glioma-inactivated protein 1, $L G I 1$; contactin-associated protein-like 2, CASPR2; $\alpha$-amino-3-hydroxy-5methyl-4-isoxazolepropionic acid receptor, AMPAR; dipeptidylpeptidase-like protein-6, $D P P X$; metabotropic glutamate receptor 5, mGluR5; anti-neuronal nuclear antibodies type 1, anti-Hu; anti-neuronal nuclear antibodies type 2, anti-Ri; anti-cytoplasmic purkinje cell antibodies, Anti-Yo; anti-glutamic acid decarboxylase, anti-GAD; anticytoplasmic purkinje cell antibodies, anti-PCA2; collapsing response mediator protein 5, CRMP5; anti-neuronal nuclear antibodies type 3, $A N N A 3$; anti-voltage-gated calcium channel, $V G C C$; human leukocyte antigen, $H L A$; gene double-stranded deoxyribonucleic acid, $d S D N A$; antiSS-A(Ro) and anti-SS-B(La) autoantibodies, Anti-SS-A and SS-B; antineutrophil cytoplasmic antibodies, anti-ANCA; cyclic peptide containing citrulline, CCP; anti-aminoacyl tRNA synthetase antibodies, anti-Jo-1; anti-recombinant $70 \mathrm{kDa}$ ribonucleoprotein, anti-RNP-70

\section{Discussion}

Based on the seizures and the abnormal psychiatric symptoms, in addition to the evidence of $\mathrm{GABA}_{\mathrm{B}}-\mathrm{R}$ antibodies detected in the CSF and serum, the patient was diagnosed with anti-GABA $A_{B}-R$ encephalitis. Our case also met the diagnostic criteria for AS by the positive HLA-B27 test and manifestations on spine and sacroiliac joint imaging. Reports on the cooccurrence of anti-GABA $\mathrm{B}_{\mathrm{B}}-\mathrm{R}$ encephalitis with tumors or another paraneoplastic neurologic disorder, such as LambertEaton myasthenic syndrome, have been published [3]. However, a literature search for reports on anti-GABA $\mathrm{B}_{\mathrm{B}} \mathrm{R}$ encephalitis or AE appearing with AS yielded nothing. Likewise, there were no reports of investigations undertaken to explain the relationship between anti-GABA $-\mathrm{R}$ encephalitis and AE with AS. Some research has suggested that T cellbased autoimmunity plays an important role in the development of anti-GABA $A_{B}-R$ encephalitis [4]. Similarly, T cells were found to act in key pathogenetic roles in AS, as well [2]. In addition, interleukin 17 (IL-17) plays a key role in inflammatory pathways and there is an evidence that IL-17 receptor-deficient mice may be protected against experimental AE. Furthermore, inflammatory disorders have also been associated with IL-17, and therapeutically targeting this 
inflammatory pathway could improve the outcome of AS patients because similar inflammatory pathways may exist between the two diseases [5].

Patients with anti-gamma-aminobutyric acid-B receptor encephalitis are frequently found to have coexisting small-cell lung cancer and some other types of tumors. Abdominal and chest CT scans performed on this patient upon admission revealed no tumor signs. However, further imaging examinations should be performed in other organs (for example, PET-CT). Unfortunately, our patient refused to undergo a PET-CT scan due to economic reasons, which limited the screening and detection of other potential tumors.

To better understand the coexistence of both diseases and to improve the prognosis, larger epidemiological studies and more research on the pathogenesis are warranted.

Acknowledgments The authors thank all participants for their participation in our study.

Author contributions A. Li and W. Feng collected the data and drafted the manuscript. J. Lin, D. Zhou, and Z. Hong conceptualized and revised the manuscript.

Funding information The study was supported by the National Natural Science Foundation of China (grants 81971213, 81671291, and 8137152).

Data availability statement Further anonymized data can be made available to qualified investigators upon request to the corresponding author.

\section{Compliance with ethical standards}

Conflict of interest The authors declare that they have no conflict of interest.

Ethical approval None.
Open Access This article is licensed under a Creative Commons Attribution 4.0 International License, which permits use, sharing, adaptation, distribution and reproduction in any medium or format, as long as you give appropriate credit to the original author(s) and the source, provide a link to the Creative Commons licence, and indicate if changes were made. The images or other third party material in this article are included in the article's Creative Commons licence, unless indicated otherwise in a credit line to the material. If material is not included in the article's Creative Commons licence and your intended use is not permitted by statutory regulation or exceeds the permitted use, you will need to obtain permission directly from the copyright holder. To view a copy of this licence, visit http://creativecommons.org/licenses/by/4.0/.

\section{References}

1. Dalmau J, Rosenfeld MR (2014) Autoimmune encephalitis update. Neuro-oncology 16(6):771-778. https://doi.org/10.1093/neuonc/nou030

2. Generali E, Bose T, Selmi C, Voncken JW, Damoiseaux J (2018) Nature versus nurture in the spectrum of rheumatic diseases: classification of spondyloarthritis as autoimmune or autoinflammatory. Autoimmun Rev 17(9):935-941. https://doi.org/10.1016/j.autrev. 2018.04.002

3. Li H, Zhang A, Hao Y, Guan H, Lv Z (2018) Coexistence of Lambert-Eaton myasthenic syndrome and autoimmune encephalitis with anti-CRMP5/CV2 and anti-GABAB receptor antibodies in small cell lung cancer: a case report. Medicine 97(19):e0696. https://doi.org/10.1097/MD.0000000000010696

4. Golombeck KS, Bönte K, Mönig C et al (2016) Evidence of a pathogenic role for $\mathrm{CD} 8+\mathrm{T}$ cells in anti-GABAB receptor limbic encephalitis. Neurol Neuroimmunol Neuroinflamm 3(3):e232. https://doi. org/10.1212/NXI.0000000000000232

5. Jaller Char JJ, Jaller JA, Waibel JS, Bhanusali DG, Bhanusali N (2018) The role of IL-17 in the human immune system and its blockage as a treatment of rheumatoid arthritis, ankylosing spondylitis, and psoriatic arthritis. J Drugs Dermatol 17(5):539-542

Publisher's note Springer Nature remains neutral with regard to jurisdictional claims in published maps and institutional affiliations. 